\title{
Feasibility of a Supporting-Salt-Free Nonaqueous Redox Flow Battery Utilizing Ionic Active Materials
}

\author{
Jarrod D. Milshtein ${ }^{+}{ }^{[a, b]}$ Sydney L. Fisher ${ }^{+}{ }^{[a, c]}{ }^{\text {Tanya M. Breault, }}{ }^{[a, c]}$ Levi T. Thompson, $^{*[a, c]}$ and \\ Fikile R. Brushett*[a, d]
}

Nonaqueous redox flow batteries (NAqRFBs) are promising devices for grid-scale energy storage, but high projected prices could limit commercial prospects. One route to reduced prices is to minimize or eliminate the expensive supporting salts typically employed in NAqRFBs. Herein, the feasibility of a flow cell operating in the absence of supporting salt by utilizing ionic active species is demonstrated. These ionic species have high conductivities in acetonitrile $\left(12-19 \mathrm{mScm}^{-1}\right)$ and cycle at $20 \mathrm{mAcm}^{-2}$ with energy efficiencies (>75\%) comparable to those of state-of-the-art NAqRFBs employing high concentrations of supporting salt. A chemistry-agnostic techno-economic analysis highlights the possible cost savings of minimizing salt content in a NAqRFB. This work offers the first demonstration of a NAqRFB operating without supporting salt. The associated design principles can guide the development of future active species and could make NAqRFBs competitive with their aqueous counterparts.

\section{Introduction}

Redox flow batteries (RFBs) have emerged as attractive devices for grid-scale energy storage owing to their decoupled power ratings (reactor area) and energy capacities (tank size), as well as their long lifetimes, location independence, and fast response. ${ }^{[1-3]}$ Widespread use of RFBs could facilitate the introduction of intermittent renewables (e.g., solar and wind) into the existing electrical grid while also providing peak-shaving and load-leveling capabilities. ${ }^{[4,5]}$ Despite these advantages, high system prices $\left(>\$ 500 \mathrm{kWh}^{-1} \text { in } 2014\right)^{[6,7]}$ have severely limited the commercial deployment of RFBs. To facilitate integration of a $4 \mathrm{~h}$ energy-storage system, the United States Department of Energy (DOE) Office of Electricity Delivery and Energy Reliability set a target price of $\$ 150 \mathrm{kWh}^{-1}$, including costs for installation and power-conditioning equipment. ${ }^{[8,9]}$ Recent techno-economic analyses predicted that both aqueous

[a] J. D. Milshtein, ${ }^{+}$S. L. Fisher, ${ }^{+}$Dr. T. M. Breault, Prof. L. T. Thompson, Prof. F. R. Brushett

Joint Center for Energy Storage Research (USA)

[b] J. D. Milshtein, ${ }^{+}$

Department of Materials Science and Engineering

Massachusetts Institute of Technology (USA)

[c] S. L. Fisher ${ }^{+}$Dr. T. M. Breault, Prof. L. T. Thompson

Department of Chemical Engineering

University of Michigan

2300 Hayward St, Ann Arbor, MI 48109 (USA)

E-mail: Itt@umich.edu

[d] Prof. F. R. Brushett

Department of Chemical Engineering

Massachusetts Institute of Technology

77 Massachusetts Ave, Cambridge, MA 02139 (USA)

E-mail:brushett@mit.edu

$\left.{ }^{+}\right]$These authors contributed equally to this work.

$\square$ Supporting Information and the ORCID identification number(s) for the

(iD author(s) of this article can be found under http://dx.doi.org/10.1002/ cssc. 201700028. and nonaqueous (NAq) RFBs could reach this aggressive target by decreasing manufacturing costs, advancing materials performance, and improving cell architecture. ${ }^{[6,10]}$ Although not commercially viable yet, NAqRFBs promise a number of advantages over aqueous systems, including broader electrochemical windows $(3-4 \mathrm{~V}),^{[1,11,12]}$ which could enable higher cell energy densities and aid in the implementation of multi-electrontransfer materials. ${ }^{[12]}$ Additionally, a wide range of NAq solvents and supporting salts are available, and rational functionalization of the active species can be used to tailor physicochemical and electrochemical properties, ${ }^{[13]}$ providing multiple pathways for device optimization and price reduction.

Future-state prices for NAq supporting electrolytes (solvent $+1 \mathrm{M}$ salt) are anticipated to be relatively high $\left(\approx \$ 5 \mathrm{~kg}^{-1}\right)$ compared to their aqueous counterparts $\left(\approx \$ 0.10 \mathrm{~kg}^{-1}\right)_{{ }^{[6]}}$ so decreasing the costs and/or quantities of both the solvent and supporting salt will be critical. ${ }^{[10]}$ A number of studies have focused on enhancing the solubility of active species, ${ }^{[14-19]}$ which serves to decrease the total amount of solvent required. ${ }^{[10]}$ The supporting salt, however, especially the fluorinated derivatives typically employed in NAq batteries (e.g., lithium hexafluorophosphate, tetrabutylammonium tetrafluoroborate), will constitute a majority of the future-state cost of supporting electrolytes $\left(\approx \$ 20 \mathrm{~kg}^{-1}\right.$ vs. $\approx \$ 2 \mathrm{~kg}^{-1}$ for the salt and solvent, respectively). ${ }^{[6]}$ Despite the opportunity for substantial cost savings, ${ }^{[10,20]}$ few studies have focused on minimizing the content of supporting salt. Previously, we described a common-ion exchange NAqRFB design that reduced the required amount of supporting salt by employing similarly charged active species that share a common counter ion. ${ }^{[20]}$ Additional cost savings are possible through the use of multifunctional materials that serve two or more critical roles in the electrolyte (i.e., solvation, charge carrier, redox active). ${ }^{[10]}$ Herein, we combine multifunc- 
tional active species with the common-ion exchange configuration to demonstrate a NAqRFB proof-of-concept prototype operating in the limit of no supporting salt.

NAqRFBs utilize supporting salts to enhance electrolyte conductivity and maintain electroneutrality during charge and discharge. ${ }^{[1,2]}$ High salt concentrations, however, can limit the solubility of the active species in the electrolyte solution, ${ }^{[20-22]}$ suppress the conductivity of ion-selective membranes, and increase area-specific resistance (ASR). ${ }^{[23]}$ The need for supporting salt can be eliminated entirely by using similarly charged active species (positive or negative) that remain as ions across all accessible states-of-charge (SOCs). In this scheme, counter ions that are associated with the redox-active ion provide charge balance, and both the active species and counter ions contribute to the ionic conductivity of the electrolyte. Figure 1

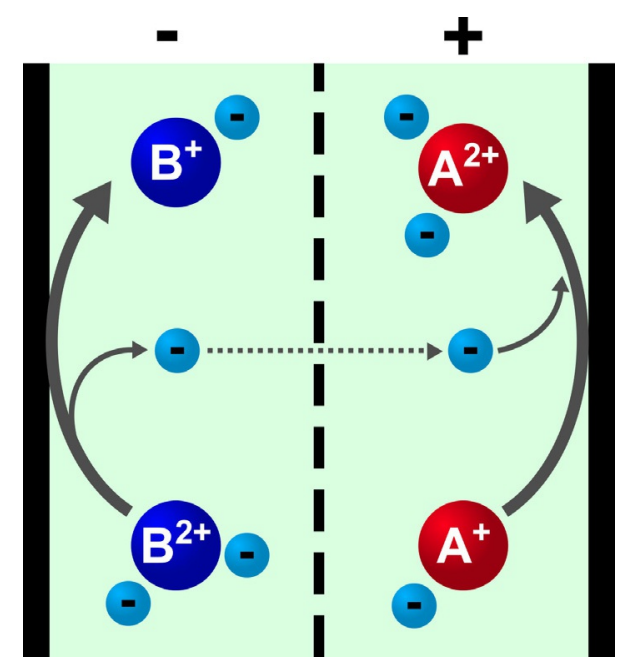

Figure 1. Schematic of the charging process in a supporting-salt-free RFB employing cationic redox-active species. $A$ is the posolyte active material (red), and B is the negolyte active material (dark blue). Associating counter anions are denoted by - (light blue).

shows the charging process for a NAqRFB utilizing cationic active species with no supporting salt, whereby counter anions are transported from the negative electrolyte (negolyte) to the positive electrolyte (posolyte) to maintain electroneutrality. The same concept can be extended to redox-active anions with counter cations.

For this study, we selected iron(II) tris(2,2'-bipyridine) tetrafluoroborate $\left(\left[\mathrm{Fe}(\mathrm{bpy})_{3}\right]\left(\mathrm{BF}_{4}\right)_{2}\right.$; see Figure $\mathrm{S} 1 \mathrm{a}$ in the Supporting Information) $)^{[24]}$ and ferrocenylmethyl dimethyl ethyl ammonium tetrafluoroborate $\left(\mathrm{Fc} 1 \mathrm{~N} 112-\mathrm{BF}_{4} \text {, Figure } \mathrm{S} 1 \mathrm{~b}\right)^{[15,16]}$ as model ionic redox-active species to demonstrate the salt-free cell concept. The lack of viable NAqRFB chemistries, especially those with the characteristics necessary for the demonstration of a salt-free device, drove our selections. Fc1N112-BF 4 is known to be a highly soluble and stable posolyte active materi-

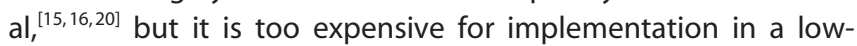
cost grid-scale device. ${ }^{[10]}\left[\mathrm{Fe}(\mathrm{bpy})_{3}\right]\left(\mathrm{BF}_{4}\right)_{2}$ is one of the few wellcharacterized NAqRFB negolyte active materials that remains as a cation across all relevant SOCs, but suffers from relatively poor stability. ${ }^{[20,24]}$ Both species have been investigated extensively in prior literature, have well-characterized properties, and are therefore excellent model compounds.

In this system, $\left[\mathrm{Fe}(\mathrm{bpy})_{3}\right]^{2+}$ and $\mathrm{Fc}_{1} 1 \mathrm{~N}_{112}{ }^{+}$act as the redoxactive cations (at $0 \% \mathrm{SOC}$ ), while $\mathrm{BF}_{4}^{-}$serves as the common, charge-balancing counter anion. The posolyte and negolyte half-cell reactions are provided in Equations (1) and (2), respectively, and Equation (3) shows the full-cell reaction:

$$
\begin{aligned}
& {[\mathrm{Fc} 1 \mathrm{~N} 112]^{2+}\left(\mathrm{BF}_{4}^{-}\right)_{2}+\mathrm{e}^{-} \rightleftharpoons[\mathrm{Fc} 1 \mathrm{~N} 112]^{+} \mathrm{BF}_{4}{ }^{-}+\mathrm{BF}_{4}{ }^{-}} \\
& {\left[\mathrm{Fe}(\mathrm{bpy})_{3}\right]^{2+}\left(\mathrm{BF}_{4}^{-}\right)_{2}+\mathrm{e}^{-} \rightleftharpoons\left[\mathrm{Fe}(\mathrm{bpy})_{3}\right]^{+} \mathrm{BF}_{4}{ }^{-}+\mathrm{BF}_{4}{ }^{-}} \\
& {\left[\mathrm{Fe}(\mathrm{bpy})_{3}\right]^{2+}\left(\mathrm{BF}_{4}^{-}\right)_{2}+[\mathrm{Fc} 1 \mathrm{~N} 112]^{+} \mathrm{BF}_{4}{ }^{-}} \\
& \rightleftharpoons\left[\mathrm{Fe}(\mathrm{bpy})_{3}\right]^{+} \mathrm{BF}_{4}{ }^{-}+[\mathrm{Fc} 1 \mathrm{~N} 112]^{2+}\left(\mathrm{BF}_{4}{ }^{-}\right)_{2}
\end{aligned}
$$

Importantly, these active species are positively charged in all relevant oxidation states, and this enables the salt-free cell configuration outlined in Figure 1. Additionally, these compounds exhibit minimal interspecies reactions in the singly charged state, are soluble in acetonitrile (MeCN), are easily synthesized in large quantities, and thus facilitate a proof-of-concept flow cell in the no-supporting-salt framework. ${ }^{[20]}$

This study demonstrates a NAqRFB configured to operate in the absence of any supporting salt, by utilizing well-studied model active species. First, conductivity measurements demonstrated the high conductivities of the model ionic active species in MeCN. Second, cyclic voltammetry and bulk electrolysis experiments showed that the ionic active species maintain redox activity in the absence of supporting salt. Third, proofof-concept flow-cell experiments demonstrated the feasibility of a supporting-salt-free NAqRFB exhibiting resistances and efficiencies similar to those of other recently reported NAqRFBs. ${ }^{[25,26]}$ Finally, a chemistry-agnostic techno-economic analysis highlighted the significant cost savings afforded by minimizing the amount of, or eliminating, salt in NAqRFBs with varying active-species costs, salt costs, and cell potentials. Overall, this paper highlights the design of a NAqRFB operating without supporting salt. Further, the design and configuration principles of NAqRFBs employing similarly charged, allionic active species outlined in this work can extend beyond the model compounds to other active species, including organic compounds, and provide a viable route to minimizing the price of promising future NAqRFBs.

\section{Results and Discussion}

\section{Active-species conductivity}

To demonstrate the feasibility of performing electrochemical experiments in MeCN solutions with no supporting salt, the conductivities of the active species were measured and compared to those of supporting salts typically employed in NAqRFBs. Figure 2 shows the high conductivities afforded by $0.2 \mathrm{M}$ of the ionic active species in $\mathrm{MeCN}$, especially in comparison to $0.2 \mathrm{M}$ lithium tetrafluoroborate $\left(\mathrm{LiBF}_{4}\right)$ and tetraethylammonium tetrafluoroborate $\left(\mathrm{TEABF}_{4}\right)$ in the same solvent. Not shown in Figure 2 is the conductivity of an equimolar solution 


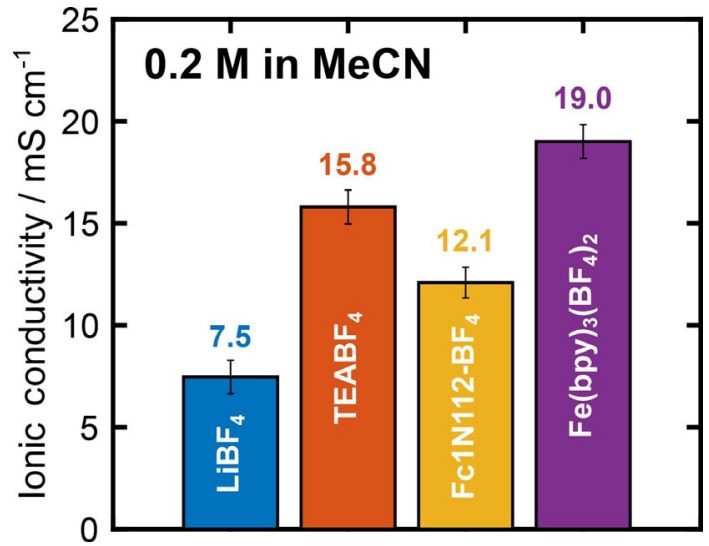

Figure 2. Comparison of electrolyte ionic conductivities for solutions containing $0.2 \mathrm{M}$ of $\mathrm{LiBF}_{4}, \mathrm{TEABF}_{4}, \mathrm{Fc} 1 \mathrm{~N} 112-\mathrm{BF}_{4}$, or $\left[\mathrm{Fe}(\mathrm{bpy})_{3}\right]\left(\mathrm{BF}_{4}\right)_{2}$ in MeCN. Error bars represent $95 \%$ confidence intervals of the standard error.

containing $\quad 0.2 \mathrm{M} \quad \mathrm{Fc} 1 \mathrm{~N} 112-\mathrm{BF}_{4} / 0.2 \mathrm{M} \quad\left[\mathrm{Fe}(\mathrm{bpy})_{3}\right]\left(\mathrm{BF}_{4}\right)_{2} / \mathrm{MeCN}$ $(0.4 \mathrm{M}$ total active species), the electrolyte composition employed later in flow-cell experiments, which is $22.5 \mathrm{mS} \mathrm{cm}^{-1}$.

The conductivities of the ionic species increase in the following order: $\mathrm{LiBF}_{4}<\mathrm{Fc} 1 \mathrm{~N} 112-\mathrm{BF}_{4}<\mathrm{TEABF}_{4}<\left[\mathrm{Fe}(\mathrm{bpy})_{3}\right]\left(\mathrm{BF}_{4}\right)_{2} . \mathrm{LiBF}_{4}$ likely exhibits the lowest conductivity because $\mathrm{Li}^{+}$is a hard acid and strongly interacts with $\mathrm{BF}_{4}^{-}$, which is a hard base. This interaction leads to a low degree of dissociation and subsequently lower ionic strength in solution for the $\mathrm{Li}^{+}$cation compared to the larger and more polarizable $\mathrm{TEA}^{+}, \mathrm{Fc} 1 \mathrm{~N}_{112}{ }^{+}$, and $\left[\mathrm{Fe}(\mathrm{bpy})_{3}\right]^{2+}$ cations. $^{[27]}\left[\mathrm{Fe}(\mathrm{bpy})_{3}\right]\left(\mathrm{BF}_{4}\right)_{2}$ exhibits higher conductivity than the other salts considered because $\left[\mathrm{Fe}(\mathrm{bpy})_{3}\right]^{2+}$ is a divalent cation, which leads to higher ionic strength of the $\left[\mathrm{Fe}(\mathrm{bpy})_{3}\right]\left(\mathrm{BF}_{4}\right)_{2}$ solution compared to those of the salts of monovalent cations. Because the conductivities of the model ionic active species $\left\{\mathrm{Fc} 1 \mathrm{~N} 112-\mathrm{BF}_{4}\right.$ and $\left.\left[\mathrm{Fe}(\mathrm{bpy})_{3}\right]\left(\mathrm{BF}_{4}\right)_{2}\right\}$ are on the same order of magnitude as that of $\mathrm{TEABF}_{4}$, a typical supporting salt for NAqRFBs, ${ }^{[1,19,25]}$ they lend themselves to implementation in electrochemical systems without supporting salt.

\section{Cyclic voltammetry}

Cyclic voltammetry was used to determine whether the active species maintain their redox activity in the absence of supporting salt, in addition to further validating that the electrolytes exhibit sufficient ionic conductivity to perform electrochemical measurements. Figure 3 (solid lines) shows cyclic voltammograms (CVs) of solutions containing the individual active spe-

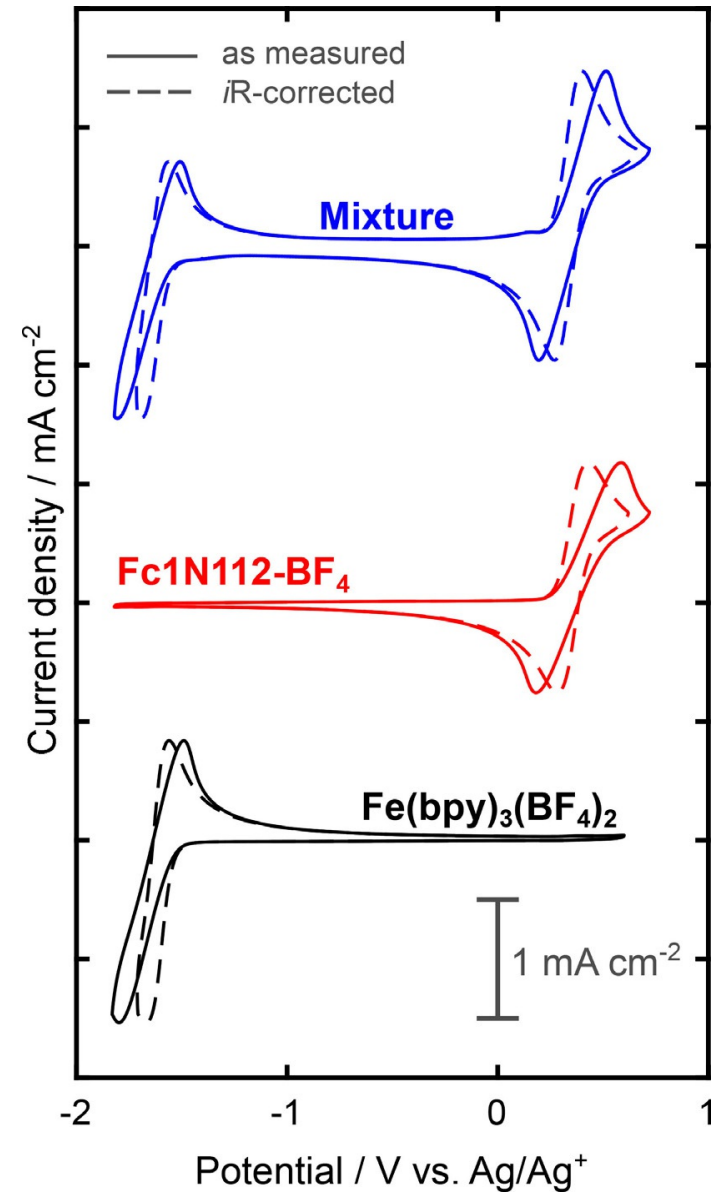

Figure 3. $\mathrm{CVs}$ of $5 \mathrm{~mm}\left[\mathrm{Fe}(\mathrm{bpy})_{3}\right]\left(\mathrm{BF}_{4}\right)_{2}, \mathrm{Fc} 1 \mathrm{~N}_{112}-\mathrm{BF}_{4}$, and an equimolar mixture of both (10 $\mathrm{mm}$ total) in MeCN with no supporting salt. For each solution, the solid lines show the data as measured, and the dashed lines represent $i R$-compensated CVs.

cies and an equimolar mixture of each in $\mathrm{MeCN}$, all without supporting salt. The redox potentials and peak-height ratios are similar to those of solutions at the same concentration in the presence of supporting salt (Table 1). ${ }^{[15,16,20,24]}$ Notably, the redox potential of $\mathrm{Fc} 1 \mathrm{~N} 112-\mathrm{BF}_{4}$ is approximately $70 \mathrm{mV}$ larger than that previously reported in a supporting electrolyte of $0.5 \mathrm{M}$ tetrabutylammonium tetrafluoroborate $\left(\mathrm{TBABF}_{4}\right) / \mathrm{MeCN}$. This discrepancy is reconciled by considering that $\mathrm{BF}_{4}^{-}$appears in the Nernst equation, and an increase in the equilibrium potential results as the supporting salt is removed.

Further analysis of the peak potentials revealed large peakto-peak separations (Table 1) in the absence of supporting salt,

\begin{tabular}{|c|c|c|c|c|c|c|}
\hline Conditions & $\begin{array}{l}5 \mathrm{~mm} \text { Fc1N112-BF } \\
\text { potential } \\
{\left[\mathrm{V} \text { vs. } \mathrm{Ag} / \mathrm{Ag}^{+}\right]}\end{array}$ & peak-height ratio & $\begin{array}{l}\text { peak separation } \\
{[\mathrm{mV}]}\end{array}$ & $\begin{array}{l}5 \mathrm{~mm}\left[\mathrm{Fe}(\mathrm{bpy})_{3}\right]\left(\mathrm{BF}_{4}\right) \\
\text { potential } \\
{\left[\mathrm{V} \text { vs. } \mathrm{Ag} / \mathrm{Ag}^{+}\right]}\end{array}$ & peak-height ratio & $\begin{array}{l}\text { peak separation } \\
{[\mathrm{mV}]}\end{array}$ \\
\hline no salt (as measured) & 0.35 & 1.0 & 405 & -1.65 & 0.9 & 310 \\
\hline no salt (iR-corrected) & 0.36 & 1.0 & 147 & -1.62 & 0.9 & 96 \\
\hline
\end{tabular}


as is anticipated owing to the lower solution conductivity with only $5 \mathrm{~mm}$ active species in MeCN. ${ }^{[28]}$ To confirm that this large peak-to-peak separation is primarily a result of low solution conductivity and not sluggish reaction kinetics, the CVs were $i R$-corrected (see dashed lines in Figure 3). The uncompensated solution resistance was measured by electrochemical impedance spectroscopy (Figure S3). The iR-corrected CVs exhibit significantly smaller peak-to-peak separations, but they are still larger than those for a solution containing $0.5 \mathrm{M} \mathrm{TBABF}_{4}{ }^{[20]}$ (Table 1). This indicates that the electrokinetics are slightly slower in the regime of low ion concentration, perhaps owing to the limited availability of anions. This interpretation is further supported by the decreased peak separation observed on addition of more active species (i.e., single species vs. the equimolar mixture). These slight differences are expected to have negligible impact during bulk cycling, especially at the high concentrations used in the flow-cell experiments. Overall, these results demonstrate that a supporting-salt-free, one-electron flow cell utilizing Fc1N112-BF 4 and $\left[\mathrm{Fe}(\mathrm{bpy})_{3}\right]\left(\mathrm{BF}_{4}\right)_{2}$ is feasible and should exhibit similar electrochemical behavior to that of a cell containing a high concentration $(\geq 0.5 \mathrm{M})$ of supporting salt. ${ }^{[20]}$

\section{Bulk electrolysis}

Bulk electrolysis experiments were performed to determine if a cell containing a mixture of $\left[\mathrm{Fe}(\mathrm{bpy})_{3}\right]\left(\mathrm{BF}_{4}\right)_{2}$ and $\mathrm{Fc} 1 \mathrm{~N} 112-\mathrm{BF}_{4}$ in $\mathrm{MeCN}$ (without supporting salt) can access the desired redox couples during cycling. Figure 4 shows capacity-retention plots and potential curves for cells cycling through
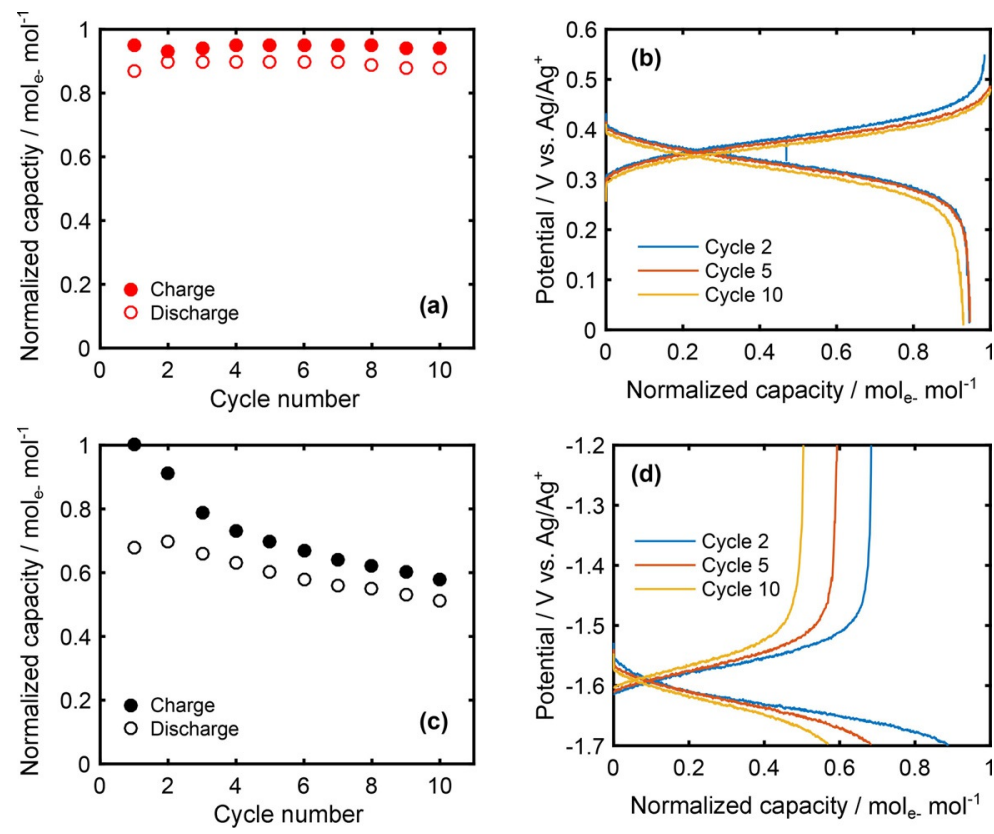

Figure 4. Bulk electrolysis of equimolar mixtures (5 mM each) of $\left[\mathrm{Fe}(\mathrm{bpy})_{3}\right]\left(\mathrm{BF}_{4}\right)_{2}$ and Fc1N112- $\mathrm{BF}_{4}$ in $\mathrm{MeCN}$, without supporting salt. a) Capacity retention of the mixture, normalized to the theoretical capacity and b) representative charge/discharge curves through a single positive electron transfer. c) Capacity retention, normalized to the theoretical capacity, and d) representative charge/discharge curves through a single negative electron transfer. a single positive or a single negative electron-transfer event. In both cases, the plateaus observed during cycling occur at the potentials expected based on the CVs (Figure 3) and demonstrate that only the desired redox couples are accessed. Furthermore, the results are consistent with those reported in the literature. ${ }^{[15,20]} \mathrm{Fc} \mathrm{N} 112-\mathrm{BF}_{4}$ exhibits no detectable capacity fade over the ten cycles (Figure $4 \mathrm{a}$ ), which is in agreement with prior reports. ${ }^{[16,20]} \mathrm{CVs}$ before and after the bulk electrolysis experiment (Figure S5) show little to no evidence of degradation. Conversely, $\left[\mathrm{Fe}(\mathrm{bpy})_{3}\right]\left(\mathrm{BF}_{4}\right)_{2}$ exhibits capacity decay over the course of the experiment owing to the irreversibility of the negative couple. ${ }^{[20]} \mathrm{CV}$ s indicate that peak heights associated with the $\left[\mathrm{Fe}(\mathrm{bpy})_{3}\right]^{2+} /\left[\mathrm{Fe}(\mathrm{bpy})_{3}\right]^{+}$couple decrease after cycling, and thus confirm active-species degradation (Figure S5). Despite the suboptimal capacity retention of $\left[\mathrm{Fe}(\mathrm{bpy})_{3}\right]\left(\mathrm{BF}_{4}\right)_{2}$, in both cases the bulk electrolysis cells access the redox couples of interest, and this confirms the feasibility of using these model active species in a proof-of-concept flow cell without supporting salt.

\section{Proof-of-concept flow cell}

The conductivities and fundamental electrochemical properties of the model ionic active species, $\left[\mathrm{Fe}(\mathrm{bpy})_{3}\right]\left(\mathrm{BF}_{4}\right)_{2}$ and $\mathrm{Fc} 1 \mathrm{~N} 112-$ $\mathrm{BF}_{4}$, are attractive for incorporation into a proof-of-concept, supporting-salt-free NAqRFB. The flow cell has a similar architecture to a high-performance all-vanadium flow cell, ${ }^{[29]}$ modified for chemical compatibility with NAq electrolytes. ${ }^{[19,30]}$ Because anion-exchange membranes exhibit limited stability in MeCN, ${ }^{[11,31]}$ Daramic was selected for use as the separator owing to its chemical stability in the electrolyte of interest, which ensures that separator degradation is not a confounding factor in evaluating flow-cell performance. Owing to the high porosity (58\%) and large characteristic pore size $(\approx 100 \mathrm{~nm})$ of this separator, crossover is expected in these experiments, so both reservoirs were filled with an equimolar $0.2 \mathrm{M}$ $\left[\mathrm{Fe}(\mathrm{bpy})_{3}\right]\left(\mathrm{BF}_{4}\right)_{2} / 0.2 \mathrm{M} \quad \mathrm{Fc} 1 \mathrm{~N} 112-\mathrm{BF}_{4} / \mathrm{MeCN}$ mixture. Prior demonstration studies on RFBs have utilized premixed electrolytes to mitigate the effects of rapid crossover in the first few cycles, ${ }^{[20,26,32]}$ although electrolytes with mixed active species would be too expensive to implement in grid-scale devices. ${ }^{[6,10]}$ One additional drawback of this configuration is the limited operating concentration of each active species. Adding supporting salt can limit the solubility of active species, ${ }^{[20-22]}$ and similar decreases are observed on addition of other ionic active species. Hence, an active-species concentration of $0.2 \mathrm{M}$ ensures that the species remain soluble at all relevant SOCs.

The flow cell also employs interdigitated flow fields (IDFFs) with carbon paper electrodes. Prior literature has suggested that IDFFs will offer the best performance for large-scale RFBs by balancing cell ASR and pressure drop. ${ }^{[29,33]}$ Additionally, thin carbonpaper electrodes offer a balance of high surface area, 

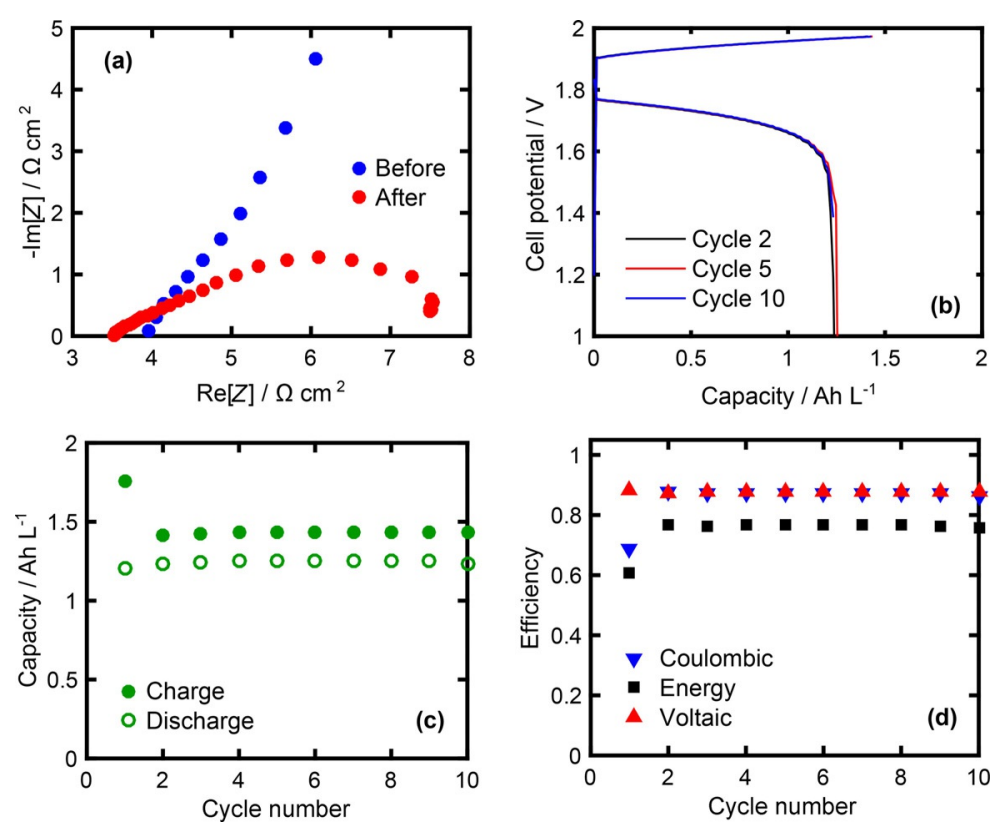

Figure 5. Cycling performance of a supporting-salt-free NAqRFB employing $0.2 \mathrm{M}[\mathrm{Fe}(\mathrm{b}$ -

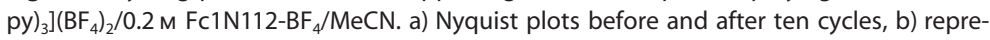
sentative charge/discharge curves, c) capacities, and d) efficiencies. The theoretical capacity is $5.36 \mathrm{AhL}^{-1}(53.6 \mathrm{mAh})$, and ten full cycles were completed in about $5.3 \mathrm{~h}$.

low ohmic losses, and facile mass transport. ${ }^{[19,34]}$ Despite the relatively thick Daramic separator $(175 \mu \mathrm{m})$, the cell exhibits an ohmic contribution $R_{\Omega}$ to the ASR of just $3.95 \Omega \mathrm{cm}^{2}$ (Figure $5 \mathrm{a}$ ) before cycling, a value similar to that reported in a prior flow-cell study employing a Daramic separator and MeCN solvent. ${ }^{[25]}$ Combining the IDFF with carbon-paper electrodes alleviates mass-transfer resistances at each electrode, ${ }^{[19]}$ and leads to a flow cell with a total ASR of $7.52 \Omega \mathrm{cm}^{2}$, determined from an impedance measurement after cycling (Figure $5 \mathrm{a}$, After). Increasing the active species concentration could further reduce mass-transfer limitations, as well as improve ionic conductivity, and subsequently decrease the ohmic contribution to the ASR as well.

Further analysis of the impedance spectra reveals that, prior to cycling, the cell exhibits an unbounded, high overall impedance (Figure $5 \mathrm{a}$, Before). Because only the fully discharged active species $\left\{\left[\mathrm{Fe}(\mathrm{bpy})_{3}\right]^{2+}\right.$ and $\left.\mathrm{Fc} 1 \mathrm{~N} 112^{+}\right\}$are present before cycling, the discharge reaction is heavily mass transfer limited and cannot proceed. After cycling, however, residual charged $\left\{\left[\mathrm{Fe}(\mathrm{bpy})_{3}\right]^{+}\right.$and $\left.\mathrm{Fc} 1 \mathrm{~N} 112^{2+}\right\}$ and discharged species allow for the electrochemical reactions to proceed in either the forward or reverse directions, and this significantly improves the masstransfer characteristics of the cell at open-circuit voltage (OCV). The bounded semicircle observed after cycling (Figure $5 \mathrm{a}$, After) represents a diffusive mass-transfer limitation through a boundary layer of finite thickness. ${ }^{[35]}$ The low-frequency intercept in the Nyquist plot exhibiting a bounded mass-transfer element (Figure $5 \mathrm{a}$, After), represents the total direct-current cell resistance at a particular SOC, and is typically a good measure of the flow-cell ASR. ${ }^{[19,25,30,36]}$

The relatively low ASR in this study compared to those reported for other $\mathrm{NAqRFBS}^{[25,26,37]}$ allows for constant-current $\mathrm{cy}$ - cling at a current density of $20 \mathrm{mAcm}^{-2}$, which is among the highest reported for NAqRFBs. ${ }^{[13,38]}$ Figure $5 \mathrm{~b}$ shows cycling curves of the proof-of-concept supporting-salt-free NAqRFB with single charge and discharge plateaus corresponding to the desired oneelectron transfer processes and a nominal cell potential of approximately $1.9 \mathrm{~V}$. To avoid accessing the additional, less-stable redox couples of $\left[\mathrm{Fe}(\mathrm{bpy})_{3}\right]\left(\mathrm{BF}_{4}\right)_{2}$ (Figure S4), ${ }^{[20,24]}$ an upper cell potential cutoff of $1.97 \mathrm{~V}$ was employed. This cutoff limited the available capacity (Figure $5 \mathrm{c}$ ) of the first cycle to $32.8 \%$ $\left(1.76 \mathrm{AhL}^{-1}\right)$ of the theoretical capacity $\left(5.36 \mathrm{AhL}^{-1}\right)$. We also limited cycling experiments to ten cycles owing to the known long-term instability of $\left[\mathrm{Fe}(\mathrm{bpy})_{3}\right]\left(\mathrm{BF}_{4}\right)_{2} \cdot{ }^{[20,24]}$ After the first cycle, the coulombic, voltaic, and energy efficiencies are constant for the remaining nine cycles, with mean values of $87.3 \pm 0.1,87.5 \pm 0.1$, and $76.4 \pm 0.1 \%$, respectively (Figure $5 d$ ).

Notably, the capacity retention during flow-cell cycling is higher than that observed during bulk electrolysis cycling for $\left[\mathrm{Fe}(\mathrm{bpy})_{3}\right]\left(\mathrm{BF}_{4}\right)_{2}$. This result is counterintuitive given the higher concentration of active species employed in the flow-cell experiment $(0.2 \mathrm{M})$ compared to the bulk electrolysis experiment $(5 \mathrm{~mm})$, but can be reconciled by considering differences in the accessed capacity. The bulk electrolysis experiments access nearly $100 \%$ of the theoretical capacity, as opposed to less than $33 \%$ for the flow-cell experiment. Because a smaller fraction of the theoretical capacity is accessed in the flow-cell experiment, deleterious side reactions associated with the less stable, reduced $\left[\mathrm{Fe}(\mathrm{bpy})_{3}\right]\left(\mathrm{BF}_{4}\right)_{2}$ species do not degrade the observed capacity as rapidly as in the bulk electrolysis experiment. This phenomenon has been reported in prior literature for battery systems with low accessed capacities. ${ }^{[39,40]}$ Although the low accessed capacity in this demonstration flow cell is not useful for a grid-scale device, the cycling results sufficiently illustrate that a flow cell operating with redox-active ions enables the complete removal of the supporting salt.

This proof-of-concept flow cell displays cycling efficiencies similar to those of state-of-the-art NAqRFBs described in the literature, ${ }^{[25,26]}$ even without any supporting salt. Moderate current density and voltaic efficiencies are achieved because of the high separator conductivity and favorable mass-transfer characteristics. The high separator conductivity is achieved by using a microporous separator, in which case the electrolyte conductivity defines the conductivity through the separator pores. Because Daramic is a passive separator, the migration of $\mathrm{BF}_{4}^{-}$anions through the separator is sufficiently rapid to afford simultaneously charge balance and moderate currents across the range of accessed SOCs. Critically, the $\mathrm{BF}_{4}{ }^{-}$anions act as both charge carriers and charge-balancing species in the relevant electrochemical reactions.

To highlight further the dual functionality of the $\mathrm{BF}_{4}{ }^{-}$anions, which are associated with the ionic redox-active species, we performed a second flow-cell cycling experiment in which $R_{\Omega}$ was recorded at every half-cycle. Figure 6 shows that $R_{\Omega}$ re- 


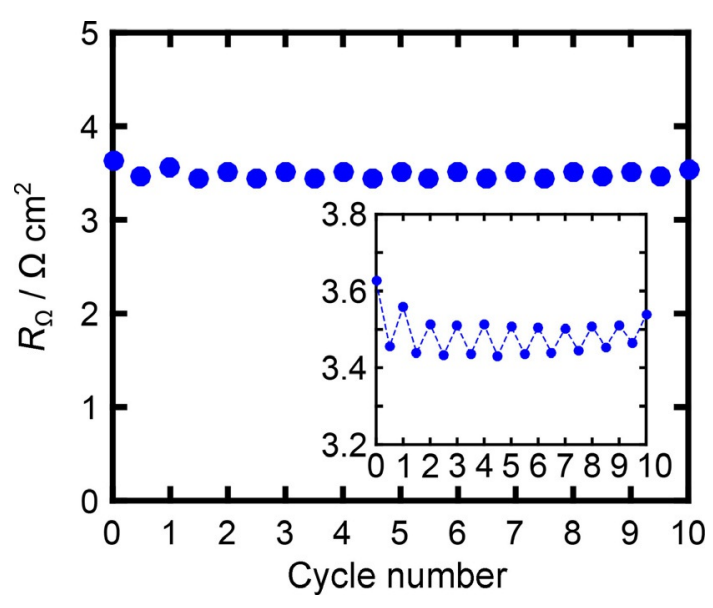

Figure 6. Ohmic contribution to cell ASR measured every half-cycle for a supporting-salt-free NAqRFB. The electrolyte composition is $0.2 \mathrm{M}[\mathrm{Fe}(\mathrm{b}-$ py) $\left.)_{3}\right]\left(\mathrm{BF}_{4}\right)_{2} / 0.2 \mathrm{M} \mathrm{Fc} 1 \mathrm{~N} 112-\mathrm{BF}_{4} / \mathrm{MeCN}$. Inset: Expansion in the $R_{\Omega}$ range of 3.2$3.8 \Omega \mathrm{cm}^{2}$, for which the dashed line serves as a visual guide. $R_{\Omega}$ is smaller in the charged state of the cell.

mains nearly constant, oscillating by $\pm 4.0 \%$ about a mean value of $3.48 \Omega \mathrm{cm}^{2}$. The small oscillations in $R_{\Omega}$ between halfcycles (inset to Figure 6) are likely caused by variations in ionpair association constants as a function of $\mathrm{SOC}^{[30,41]}$ causing subsequent changes in the effective conductivity of the separator and porous electrodes. Oscillations in electrolyte conductivity as a function of SOC are common during RFB cycling, as demonstrated for the all-vanadium $\mathrm{RFB}^{[41]}$ and quantified in one study on a NAqRFB electrolyte. ${ }^{[30]}$ Ultimately, the data in Figure 6 point to a cell devoid of supporting salt that maintains $R_{\Omega}$ values comparable to those in the contemporary literature. $^{[25]}$

\section{Chemistry-agnostic techno-economic analysis of salt-free NAqRFBs}

To investigate the financial benefits of removing, or minimizing, the supporting-salt requirement in NAqRFB electrolytes, we performed a chemistry-agnostic techno-economic analysis to quantify how salt cost and concentration affect battery price. Techno-economic analysis is a powerful tool for evaluating the price performance of an energy-storage system by relating the total battery price to material properties, electrochemical performance, and component cost parameters. Given that the proof-of-concept flow cell does not have sufficiently stable or cheap active materials, as well as an insufficient cell potential, we developed a chemistry-agnostic representation that illustrates the cost savings afforded by minimizing supporting-salt concentration for a variety of active-species costs, salt costs, and cell potentials.

We employed a prior model developed by Dmello et al., ${ }^{[10]}$ which considers the contributions of reactor cost $C_{r}$ electrolyte cost $C_{\mathrm{el}}$, additional cost $C_{\mathrm{add}}$, and balance-of-plant (BOP) cost $C_{\text {BOP }}$ to the battery price per unit energy $\left(P_{0} / E_{\mathrm{d}}\left[\$ \mathrm{kWh}^{-1}\right]\right)$, as shown in Equation (4). The reactor cost incorporates the costs of bipolar plates, membranes, and seals, as well as the reactor ASR and battery discharge time. The BOP costs account for auxiliary equipment such as pumps, sensors, tanks, pipes, and heat exchangers, while the additional costs account for overhead, labor, profit margin, and depreciation. Detailed assumptions and calculations of the reactor, additional, and BOP costs are available elsewhere. ${ }^{[6,10]}$ Note that this work considers a future-state price for a battery with $5 \mathrm{~h}$ discharge time, ${ }^{[6,8-10]}$ which does not include the cost of installation or power-conditioning systems (e.g., inverter), as opposed to a system price that does incorporate such costs. ${ }^{[10]}$ A prior RFB cost modeling study has estimated that installation and power-conditioning systems would contribute future-state costs of $\$ 30$ and $\$ 20 \mathrm{kWh}^{-1}$ ( $\$ 100 \mathrm{~kW}^{-1}$ over $5 \mathrm{~h}$ discharge), respectively, to the RFB system price. ${ }^{[6]}$ Hence, to achieve the DOE system price target of $\$ 150 \mathrm{kWh}^{-1},[8,9]$ we can afford a battery price of $\$ 100 \mathrm{kWh}^{-1}$. ${ }^{10]}$

$\frac{P_{0}}{E_{\mathrm{d}}}=C_{\mathrm{r}}+C_{\mathrm{el}}+C_{\mathrm{add}}+C_{\mathrm{BOP}}$

To calculate the electrolyte cost, a detailed model [Eq. (5)] explicitly accounts for the costs associated with the electrolyte materials, namely the active species, solvent, and salt. ${ }^{[10]}$ The electrolyte material costs are comprised of the following parameters: $M\left[\mathrm{~kg} \mathrm{~mol}^{-1}\right]$ is the molar mass of the active species, $s$ the stoichiometric coefficient of the discharge reaction, $\chi$ the depth-of-discharge, $n_{\mathrm{e}}$ the number of electrons stored per mole active material, $c_{\mathrm{m}}\left[\$ \mathrm{~kg}^{-1}\right]$ the active-species cost per unit mass, $b\left[\mathrm{~mol} \mathrm{~kg}^{-1}\right]$ the harmonic mean molality of the active species across both electrodes, $c_{\text {sol }}\left[\$ \mathrm{~kg}^{-1}\right]$ the solvent cost per unit mass, $M_{\text {salt }}\left[\mathrm{kg} \mathrm{mol}^{-1}\right]$ the molar mass of the salt, $c_{\text {salt }}\left[\mathrm{kg}^{-1}\right]$ the salt cost per unit mass, and $r_{\text {salt }}$ the arithmetic mean ratio of moles of salt per mole of active species across both electrodes. The $+/$ - subscripts denote the posolyte and negolyte active materials, respectively. The electrolyte materials costs are normalized by the total discharge energy of the battery, encompassed by the following additional parameters: $F$ [kAh $\left.\mathrm{mol}^{-1}\right]$ is the Faraday constant, $U$ [V] the cell potential, and $\varepsilon_{\mathrm{e}^{\prime}} \varepsilon_{\mathrm{q}}$, and $\varepsilon_{\mathrm{v}}$ are the energy, coulombic, and voltaic efficiencies, respectively. Here we assume an active-species molality of $3 \mathrm{~mol} \mathrm{~kg}^{-1}$. Assumptions for the values of all other parameters not outlined in this work are described in detail by Dmello et al. ${ }^{[10]}$

$$
C_{\mathrm{el}}=\frac{1}{\varepsilon_{\mathrm{e}} \varepsilon_{\mathrm{q}} F \varepsilon_{\mathrm{v}} U}\left(\frac{s_{+} M_{+}}{\chi_{+} n_{\mathrm{e}+}} c_{\mathrm{m},+}+\frac{s_{-} M_{-}}{\chi_{-} n_{\mathrm{e}-}} c_{\mathrm{m},-}+\frac{2}{b} c_{\mathrm{sol}}+2 r_{\text {salt }} M_{\text {salt }} c_{\text {salt }}\right)
$$

To illustrate the benefits of reducing salt cost contributions, we define the salt cost factor $C_{\text {salt }}^{\$}$ and the active-material cost factor $C_{m}^{\$}$ in Equations (6) and (7), respectively, both of which have units of dollars per mole electrons:

$$
\begin{aligned}
& C_{\text {salt }}^{\$}=2 r_{\text {salt }} M_{\text {salt }} C_{\text {salt }} \\
& C_{\mathrm{m}}^{\$}=\frac{s M}{\chi n_{\mathrm{e}}} C_{\mathrm{m}}
\end{aligned}
$$

Figure 7 shows the relationship between battery price and the salt cost factor for various cell potentials and active-materi- 


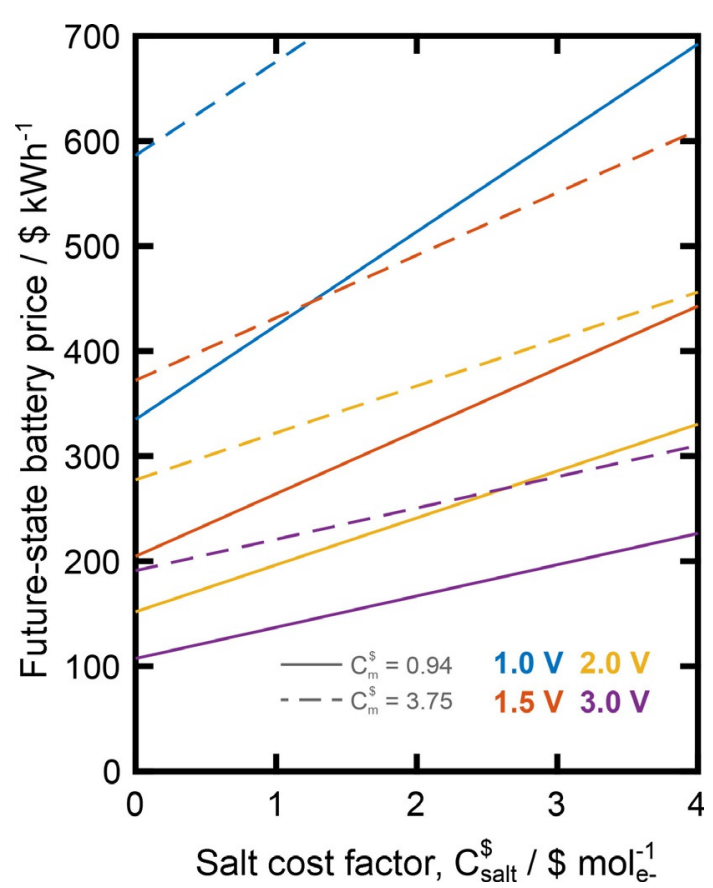

Figure 7. Future-state battery price as a function of salt cost factor $C_{\text {salt }}^{5}$ for various cell potentials $U$. Solid lines denote active-material cost factors of $C_{m}^{\$}=0.94$, while dashed lines denote $C_{m}^{\$}=3.75$. As practical examples, consider a cell with a depth of discharge $\chi$ of $80 \%$, stoichiometric coefficients $s$ equal to 1 , and active-material molecular weight $M$ of $150 \mathrm{~g} \mathrm{~mol}^{-1}$. Then, $C_{m}^{\$}=0.94$ would represent an active material with a cost $C_{m}$ of $\$ 5 \mathrm{~kg}^{-1}$, and $C_{\mathrm{m}}^{\$}=3.75$ an active material with a cost of $\$ 20 \mathrm{~kg}^{-1}$. Further, $C_{\text {salt }}^{\$}=2$ could represent a salt with molecular weight $M_{\text {salt }}$ of $100 \mathrm{~g} \mathrm{~mol}^{-1}$ and cost $c_{\text {salt }}$ of $\$ 20 \mathrm{~kg}^{-1}$ dissolved in a ratio of $0.5 \mathrm{~mol}$ of salt per mole active species $\left(r_{\text {salt }}=0.5\right)$.

al cost factors. In general, as cell potential decreases, the battery price reduces more rapidly with decreasing $C_{\text {salt' }}^{\$}$ that is, RFB price becomes more sensitive to variations in $C_{\text {salt }}^{\$}$ at lower cell potentials. Furthermore, battery price rises with increasing $C_{\text {salt, }}^{\$}$ but variations in $C_{m}^{\$}$ do not affect the slopes of the price curves in Figure 7. Critically, to achieve the recommended battery price of $\$ 100 \mathrm{kWh}^{-1},{ }^{[10]} \mathrm{NAqRFBs}$ will require high cell potentials near $3 \mathrm{~V}$ and values of $C_{\text {salt }}^{\$}$ near zero, ${ }^{[6,10]}$ the combination of which has yet to be experimentally realized. Decreasing the molecular weight of the salt (small $M_{\text {salt }}$ ) or identifying cheap salts (small $C_{\text {salt }}$ ) are two strategies to decrease $C_{\text {salt }}^{\$}$, but considering the prevalence of salts with fluorinated anions in literature NAqRFBs, identifying salts with molecular weights lower than that of $\mathrm{LiBF}_{4}\left(93.75 \mathrm{~g} \mathrm{~mol}^{-1}\right)$ or costs under $\$ 20 \mathrm{~kg}^{-1[6]}$ seems unlikely in the short term. In this work, we pursued a third option of minimizing $r_{\text {salt }}$ by removing the salt altogether and setting $r_{\text {salt }}=0$, which Figure 7 and Equation (5) show is a powerful pathway towards economically viable NAqRFBs.

\section{Conclusions}

We have presented a proof-of-concept NAqRFB operating in the absence of supporting salt, by utilizing $\mathrm{Fc} \mathrm{N} 112-\mathrm{BF}_{4}$ and $\left[\mathrm{Fe}(\mathrm{bpy})_{3}\right]\left(\mathrm{BF}_{4}\right)_{2}$ as model ionic active materials. Efficiencies comparable to those of state-of-the-art NAqRFBs that employ high concentrations of supporting salt are observed over ten cycles at a moderate current density $\left(20 \mathrm{~mA} \mathrm{~cm}^{-2}\right)$. This operation is possible owing to the high conductivities of the active species in $\mathrm{MeCN}$, which remain as ions across all relevant

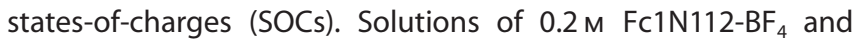
$\left[\mathrm{Fe}(\mathrm{bpy})_{3}\right]\left(\mathrm{BF}_{4}\right)_{2}$ in $\mathrm{MeCN}$ exhibit conductivities of 12.1 and $19.0 \mathrm{mS} \mathrm{cm}^{-1}$, respectively, which are about two times higher than that of $0.2 \mathrm{M} \mathrm{LiBF}_{4}$ and comparable to that of $0.2 \mathrm{M}$ $\mathrm{TEABF}_{4}$ in the same solvent. Furthermore, a chemistry-agnostic techno-economic analysis highlighted the potential cost savings of minimizing salt content in NAqRFBs of varying activematerial cost, salt cost, and cell potential. Overall, this paper offers proof of concept of a NAqRFB operating without supporting salt, and opens a pathway for exceptional performance and cost savings.

Although the model active species employed in this work are too expensive or unstable for practical grid implementation, ${ }^{[6,10,20,24]}$ our investigation highlights the promise of utilizing ionic redox-active species to enable cost-effective NAqRFBs without sacrificing performance. Designing cheaper counter anions to replace the existing, expensive fluorinated options (e.g., tetrafluoroborate, hexafluorophosphate) could lead to additional cost savings. Further, ionic modification of otherwise neutral redox-active compounds, ${ }^{[15,16]}$ or implementation of deep-eutectic redox-active melts, ${ }^{[42-44]}$ could be powerful approaches in realizing electrolytes with low salt content. Redoxactive ionic liquids, ${ }^{[45,46]}$ adapted for flow-battery applications, represent an extreme realization of the supporting-salt-free concept by enabling ultrahigh concentration or even solventfree electrolytes. Tailoring ionic active species to display desirable physicochemical (i.e., high solubility, ${ }^{[13]}$ low viscosity) and electrochemical properties (i.e., extreme redox potentials, ${ }^{[10]}$ stability ${ }^{[13]}$ ) will enable the extension of the supporting-saltfree concept to more practical NAqRFB prototypes.

\section{Experimental Section}

\section{Materials}

All solution preparation and electrochemical experiments were performed inside argon-filled gloveboxes $\left(\mathrm{O}_{2}<5 \mathrm{ppm}, \mathrm{H}_{2} \mathrm{O}<1 \mathrm{ppm}\right)$. MeCN (Extra Dry, 99.9\%) was purchased from Acros Organics. Tetraethylammonium tetrafluoroborate $(99.9 \%)$ and lithium tetrafluoroborate $(99.9 \%)$ were purchased from BASF and used as received.

\section{Synthesis of active species}

All reagents and starting materials [iron(II) tetrafluoroborate hexahydrate $(97 \%)$, (dimethylaminomethyl)ferrocene $(96 \%)$, bromoethane $(98 \%)$, sodium tetrafluoroborate $(98 \%)]$ were purchased from Sigma-Aldrich, with the exception of 2,2'-bipyridine (98\%, Alfa Aesar), and used as received. $\left[\mathrm{Fe}(\mathrm{bpy})_{3}\right]\left(\mathrm{BF}_{4}\right)_{2}$ was prepared according to a literature procedure. ${ }^{[2]} \mathrm{Fc} 1 \mathrm{~N} 112-\mathrm{BF}_{4}$ was synthesized via a bromide salt intermediate, also as reported in literature. ${ }^{[15,16,20]}$ lon exchange of $\mathrm{Br}^{-}$with $\mathrm{BF}_{4}^{-}$was performed in deionized water to afford the final product. ${ }^{[20]}$ 


\section{Conductivity measurements}

Electrolyte conductivity measurements were performed with a two-electrode, Swagelok-style conductivity cell that has been described previously. ${ }^{[30]}$ The conductivity cell was filled with electrolyte $(600 \mu \mathrm{L})$ and then sealed. The impedance of the conductivity cell was measured over a small frequency range $(1 \mathrm{MHz}$ to $100 \mathrm{~Hz}$ ) about the OCV with a potential amplitude of $10 \mathrm{mV}$. The high-frequency intercept of the Nyquist plot was used as the cell resistance value for subsequent calculations of electrolyte conductivity. Cell resistances were measured ten times for three aliquots of each electrolyte composition. Between measurements, the conductivity cell was rinsed with pure $\mathrm{MeCN}$. The conductivity cell was calibrated in an ice/water bath $\left(0^{\circ} \mathrm{C}\right)$ outside of the glovebox to build a four-point calibration curve (Figure S2), by using the following aqueous sodium chloride standards $\left(\right.$ Orion $^{\mathrm{TM}}$ ): 0.100, 1.413, 12.90, and $111.9 \mathrm{mS} \mathrm{cm}^{-1}$. NAq electrolyte conductivities were determined from cell resistance measurements and the calibration curve. Error bars for electrolyte conductivities represent $95 \%$ confidence intervals of the standard error, accounting for the experimental uncertainties, measurement noise, repeatability, and quality of the calibration fit.

\section{Cyclic voltammetry}

CVs were recorded with a BioLogic VSP potentiostat in a custom $10 \mathrm{~mL}$ three-electrode electrochemical cell. A $3 \mathrm{~mm}$-diameter glassy carbon disk was used as the working electrode (BASi) a coiled platinum wire as the counter electrode, and a fritted Ag/ $\mathrm{Ag}^{+}$quasireference electrode (BASi) filled with silver tetrafluoroborate $(0.01 \mathrm{M}, 98 \%$, Sigma-Aldrich) in MeCN. CVs were recorded at a scan rate of $100 \mathrm{mV} \mathrm{s}^{-1}$ in $\mathrm{MeCN}$ solutions containing the individual active species $(5 \mathrm{~mm})$ or an equimolar mixture containing both $\left[\mathrm{Fe}(\mathrm{bpy})_{3}\right]\left(\mathrm{BF}_{4}\right)_{2}$ and $\mathrm{Fc} 1 \mathrm{~N} 112-\mathrm{BF}_{4}$ (10 mM total). Impedance measurements were recorded about OCV over a frequency range of $1 \mathrm{MHz}$ to $1 \mathrm{~Hz}$ with a potential amplitude of $10 \mathrm{mV}$.

\section{Bulk electrolysis}

Bulk electrolysis experiments were performed in a custom glass $\mathrm{H}$ type cell comprising two electrolyte chambers $(5 \mathrm{~mL})$, separated by an ultrafine glass frit (P5, Adams and Chittenden) to minimize crossover, as described in prior literature. ${ }^{[20]}$ Both chambers were stirred continuously during cycling. Reticulated vitreous carbon (100 PPI, Duocell) was used as the working and counter electrodes, with a fritted $\mathrm{Ag} / \mathrm{Ag}^{+}$quasireference electrode. A BioLogic VSP potentiostat was used to apply a constant current equivalent to a Crate of $1 \mathrm{C}(0.67 \mathrm{~mA})$. Potential cutoffs $(0.55$ to $0 \mathrm{~V}$ and -1.7 to $-1.2 \mathrm{~V}$ for the positive and negative experiments, respectively) and a $100 \%$ SOC coulombic cutoff were used during cycling. A $3 \mathrm{~mm}$ diameter glassy carbon working electrode (BASi) was used to record CVs before and after cycling. For each test, both active species (10 mM total) were dissolved in MeCN.

\section{Flow cells}

The flow cell used in this study is similar to those in previous reports (Figure S6), ${ }^{[19,30]}$ with IDFFs and a geometric active area of $2.55 \mathrm{~cm}^{2}$. Flow cells were assembled outside of the glovebox and then dried under vacuum $\left(-91 \mathrm{kPa}_{\mathrm{g}}\right)$ for at least $1 \mathrm{~h}$ before beginning experiments; all electrochemical measurements were performed inside the glovebox. Backing plates were machined from polypropylene, and flow fields were machined from $3.18 \mathrm{~mm}$-thick impregnated graphite (G347B graphite, MWI, Inc.). Electrodes were cut $(16.1 \mathrm{~mm} \times 14.1 \mathrm{~mm})$ from $190 \pm 30 \mu \mathrm{m}$-thick carbon paper (25 AA, SGL Group) and used as received, without any pretreatment. Carbon-paper electrodes were layered two pieces thick and compressed by $20 \pm 2 \%$ in the assembled flow cell to yield a final total compressed electrode thickness of $304 \pm 49 \mu \mathrm{m}$. A single layer of Daramic 175 was used as received as the cell separator. Teflon gaskets sealed the separator and electrodes inside the cell. Sealed jars (10 mL, Savillex), made from perfluoroalkoxy alkane (PFA), served as the electrolyte reservoirs. A peristaltic pump (Masterflex $\mathrm{L} / \mathrm{S}$ Series) was used to drive electrolyte through the flow cell and reservoirs. Norprene tubing (Masterflex) was used inside the peristaltic pump head. PFA tubing (Swagelok) linked together the pump head, flow cell, and reservoirs. All tubing connections were made with pressure-rated PFA (Swagelok), Teflon (Swagelok), or stainless steel (McMaster-Carr) compression fittings. All tubing had an inner diameter of $1.6 \mathrm{~mm}$ (Figure S7). All flow-cell materials (polypropylene, impregnated graphite, PFA, Teflon, stainless steel, and Daramic) were selected in part owing to their chemical compatibility with $\mathrm{MeCN}$.

Premixed electrolyte $(10 \mathrm{~mL})$ containing $\left[\mathrm{Fe}(\mathrm{bpy})_{3}\right]\left(\mathrm{BF}_{4}\right)_{2} \quad(0.2 \mathrm{M}) /$

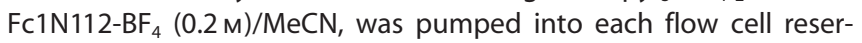
voir. For the redox couples accessed, the theoretical capacity of the electrolyte was $5.36 \mathrm{AhL}^{-1}(53.6 \mathrm{mAh})$. During the first flowcell cycling experiment, a constant current density of $20 \mathrm{mAcm}^{-2}$ (51 mA) was applied, and cell-potential cutoffs of 1.00-1.97 V were imposed. The upper voltage cutoff was selected to avoid accessing additional, unstable redox couples of $\left[\mathrm{Fe}(\mathrm{bpy})_{3}\right]\left(\mathrm{BF}_{4}\right)_{2}$, and the lower voltage cutoff ensured complete discharge of the cell. The cell was cycled ten times over approximately $5.3 \mathrm{~h}$. Flow-cell impedance measurements before and after the first flow-cell experiment were recorded about OCV over a frequency range of $100 \mathrm{kHz}$ to $5 \mathrm{mHz}$, with a potential amplitude of $10 \mathrm{mV}$. A second flow-cell cycling experiment was performed in which constant-current cycling $\left(20 \mathrm{~mA} \mathrm{~cm}^{-2}\right)$ was paused at each half-cycle to measure flowcell impedance in a higher-frequency regime (100 kHz to $20 \mathrm{~Hz})$.

\section{Acknowledgements}

J.D.M. and S.L.F. contributed equally to this work. This project was supported by the Joint Center for Energy Storage Research (JCESR), an Energy Innovation Hub funded by the United States Department of Energy. J.D.M. and S.L.F. acknowledge the National Science Foundation Graduate Research Fellowship Program for additional funding. We thank Dr. Kyle Smith and Rylan Dmello from the University of Illinois at Urbana-Champaign for their assistance developing the MATLAB code used to perform the techno-economic analysis. We also thank other members of the JCESR Flow Chemistry team, including Dr. Xiaoliang Wei, Dr. Rama Vemuri, Dr. Wentao Duan, Dr. Robert Darling, Dr. Krista Hawthorne, and Vinay lyer. Finally, we appreciate the valuable feedback from members of the Thompson Group at the University of Michigan and the Brushett Group at the Massachusetts Institute of Technology throughout the project.

\section{Conflict of interest}

The authors declare no conflict of interest. 
Keywords: electrochemistry • energy storage $\cdot$ nonaqueous flow batteries - redox chemistry $\cdot$ techno-economic analysis

[1] W. Wang, Q. Luo, B. Li, X. Wei, L. Li, Z. Yang, Adv. Funct. Mater. 2013, 23, $970-986$.

[2] A. Z. Weber, M. M. Mench, J. P. Meyers, P. N. Ross, J. T. Gostick, Q. Liu, J. Appl. Electrochem. 2011, 41, 1137-1164.

[3] M. Skyllas-Kazacos, M. H. Chakrabarti, S. A. Hajimolana, F. S. Mjalli, M. Saleem, J. Electrochem. Soc. 2011, 158, R55-R79.

[4] P. Denholm, E. Ela, B. Kirby, M. Milligan, The Role of Energy Storage with Renewable Electricity Generation: NREL/TP-6A2-47187, 2010.

[5] B. Dunn, H. Kamath, J. M. Tarascon, Science 2011, 334, 928-935.

[6] R. M. Darling, K. G. Gallagher, J. A. Kowalski, S. Ha, F. R. Brushett, Energy Environ. Sci. 2014, 7, 3459-3477.

[7] V. Viswanathan, A. Crawford, D. Stephenson, S. Kim, W. Wang, B. Li, G. Coffey, E. Thomsen, G. Graff, P. Balducci, M. Kintner-Meyer, V. Sprenkle, J. Power Sources 2014, 247, 1040-1051.

[8] D. Rastler, Market Driven Distributed Energy Storage Requirements for Load Management Applications, Electric Power Research Institute, Palo Alto, CA, 2007.

[9] U.S. Department of Energy: Office of Electricity Delivery and Energy Reliability, Energy Storage: Program Planning Document, 2011.

[10] R. D. Dmello, J. D. Milshtein, F. R. Brushett, K. C. Smith, J. Power Sources 2016, 330, $261-272$

[11] S. H. Shin, S. H. Yun, S. H. Moon, RSC Adv. 2013, 3, 9095-9116.

[12] W. Wang, V. Sprenkle, Nat. Chem. 2016, 8, 204-206.

[13] J. A. Kowalski, L. Su, J. D. Milshtein, F. R. Brushett, Curr. Opin. Chem. Eng. 2016, 13, 45-52.

[14] J. Huang, L. Cheng, R. S. Assary, P. Wang, Z. Xue, A. K. Burrell, L. A. Curtiss, L. Zhang, Adv. Energy Mater. 2015, 5, 1401782.

[15] L. Cosimbescu, X. Wei, M. Vijayakumar, W. Xu, M. L. Helm, S. D. Burton, C. M. Sorensen, J. Liu, V. Sprenkle, W. Wang, Sci. Rep. 2015, 5, 14117.

[16] X. Wei, L. Cosimbescu, W. Xu, J. Z. Hu, M. Vijayakumar, J. Feng, M. Y. Hu, X. Deng, J. Xiao, J. Liu, V. Sprenkle, W. Wang, Adv. Energy Mater. 2015, 5, 1400678.

[17] P. J. Cabrera, X. Yang, J. A. Suttil, K. L. Hawthorne, R. E. M. Brooner, M. S. Sanford, L. T. Thompson, J. Phys. Chem. C 2015, 119, 15882-15889.

[18] P. J. Cabrera, X. Yang, J. A. Suttil, R. E. M. Brooner, L. T. Thompson, M. S. Sanford, Inorg. Chem. 2015, 54, 10214-10223.

[19] J. D. Milshtein, A. P. Kaur, M. D. Casselman, J. A. Kowalski, S. Modekrutti, P. Zhang, N. H. Attanayake, C. F. Elliott, S. R. Parkin, C. Risko, F. R. Brushett, S. A. Odom, Energy Environ. Sci. 2016, 9, $3531-3543$.

[20] S. M. Laramie, J. D. Milshtein, T. M. Breault, F. R. Brushett, L. T. Thompson, J. Power Sources 2016, 327, $681-692$.

[21] A. A. Shinkle, T. J. Pomaville, A. E. S. Sleightholme, L. T. Thompson, C. W. Monroe, J. Power Sources 2014, 248, 1299-1305.

[22] J. R. Dahn, J. Jiang, L. M. Moshurchak, M. D. Fleischauer, C. Buhrmester, L. J. Krause, J. Electrochem. Soc. 2005, 152, A1283-A1289.

[23] L. Su, R. M. Darling, K. G. Gallagher, W. Xie, J. L. Thelen, A. F. Badel, J. L. Barton, K. J. Cheng, N. P. Balsara, J. S. Moore, F. R. Brushett, J. Electrochem. Soc. 2016, 163, A5253-A5262.
[24] M. H. Chakrabarti, R. A. W. Dryfe, E. P. L. Roberts, Electrochim. Acta 2007, 52, 2189-2195

[25] I. L. Escalante-Garcia, J. S. Wainright, L. T. Thompson, R. F. Savinell, J. Electrochem. Soc. 2015, 162, A363-A372.

[26] X. Wei, W. Xu, J. Huang, L. Zhang, E. Walter, C. Lawrence, M. Vijayakumar, W. A. Henderson, T. Liu, L. Cosimbescu, B. Li, V. Sprenkle, W. Wang, Angew. Chem. Int. Ed. 2015, 54, 8684-8687; Angew. Chem. 2015, 127 8808-8811.

[27] M. Ue, J. Electrochem. Soc. 1994, 141, 3336.

[28] S. R. Belding, R. G. Compton, J. Electroanal. Chem. 2012, 683, 1-13.

[29] R. M. Darling, M. L. Perry, J. Electrochem. Soc. 2014, 161, A1381-A1387.

[30] J. D. Milshtein, J. L. Barton, R. M. Darling, F. R. Brushett, J. Power Sources 2016, 327, $151-159$.

[31] N. S. Hudak, L. J. Small, H. D. Pratt, T. M. Anderson, J. Electrochem. Soc. 2015, 162, A2188-A2194.

[32] Y. K. Zeng, X. L. Zhou, L. An, L. Wei, T. S. Zhao, J. Power Sources 2016 $324,738-744$.

[33] C. R. Dennison, E. Agar, B. Akuzum, E. C. Kumbur, J. Electrochem. Soc 2016, 163, A5163-A5169.

[34] Q. H. Liu, G. M. Grim, A. B. Papandrew, A. Turhan, T. A. Zawodzinski, M. M. Mench, J. Electrochem. Soc. 2012, 159, A1246-A1252.

[35] X.-Z. Yuan, C. Song, H. Wang, J. Zhang, Fundam. Appl. London 2010.

[36] C.-N. Sun, F. M. Delnick, D. S. Aaron, A. B. Papandrew, M. M. Mench, T. A. Zawodzinski, J. Electrochem. Soc. 2014, 161, A981-A988.

[37] M. Park, N. Lee, S. Lee, K. J. Kim, D. Oh, Y. Kim, ACS Appl. Mater. Interfaces 2014, 6, 10729-10735.

[38] W. Duan, R. S. Vemuri, J. D. Milshtein, S. Laramie, R. D. Dmello, J. Huang L. Zhang, D. Hu, M. Vijayakumar, W. Wang, J. Liu, R. M. Darling, L. Thompson, K. Smith, J. S. Moore, F. R. Brushett, X. Wei, J. Mater. Chem. A 2016, 4, 5448-5456.

[39] A. J. Smith, J. C. Burns, D. Xiong, J. R. Dahn, J. Electrochem. Soc. 2011, 158, A1136-A1142.

[40] A. Orita, M. G. Verde, M. Sakai, Y. S. Meng, J. Power Sources 2016, 321, $126-134$.

[41] M. Skyllas-Kazacos, M. Kazacos, J. Power Sources 2011, 196, 8822-8827.

[42] M. A. Miller, J. S. Wainright, R. F. Savinell, J. Electrochem. Soc. 2016, 163, A578-A579.

[43] L. Bahadori, M. A. Hashim, N. S. A. Manan, F. S. Mjalli, I. M. AlNashef, N. P. Brandon, M. H. Chakrabarti, J. Electrochem. Soc. 2016, 163, A632-A638.

[44] M. H. Chakrabarti, F. S. Mjalli, I. M. AlNashef, M. A. Hashim, M. A. Hussain L. Bahadori, C. T. J. Low, Renewable Sustainable Energy Rev. 2014, 30, 254-270.

[45] E. Mourad, L. Coustan, S. A. Freunberger, A. Mehdi, A. Vioux, F. Favier, O. Fontaine, Electrochim. Acta 2016, 206, 513-523.

[46] J. Park, M. Lee, S. Hwang, D. Lee, D. Oh (Samsung Electronics Co., Ltd, Suwon), US2012/0171541A1, 2012.

Manuscript received: January 6, 2017

Accepted Article published: February 8, 2017

Final Article published: March 30, 2017 